\title{
Salivary cortisol during memory encoding in pregnancy predicts postpartum depressive symptoms: a longitudinal study
}

\author{
Cortisol salivar durante aquisição de memória na gravidez prediz sintomas \\ depressivos no período pós-parto: um estudo longitudinal
}

Marissa E. Williams ${ }^{1}$ Benicio N. Frey ${ }^{1,2,3}$

\begin{abstract}
Introduction: Postpartum depression (PPD) is a common disorder that substantially decreases quality of life for both mother and child. In this longitudinal study, we investigated whether emotional memory, salivary cortisol (SCORT) or alphaamylase during pregnancy predict postpartum depressive symptoms.

Methods: Forty-four pregnant women (14 euthymic women with a diagnosis of major depressive disorder [MDD] and 30 healthy women) between the ages of 19 and 37 years (mean age = $29.5 \pm 4.1$ years) were longitudinally assessed in the 2 nd trimester of pregnancy (12-22 weeks of gestational age) and again at 1417 weeks postpartum. Depressive symptoms were assessed using the Edinburgh Postnatal Depression Scale (EPDS).

Results: Follow-ups were completed for 41 women (7\% attrition). Postpartum EPDS scores were predicted by SCORT collected immediately after an incidental encoding memory task during pregnancy $\left(b=-0.78, t_{-2.14}, p=0.04\right)$. Postpartum EPDS scores were not predicted by positive $(p=0.27)$ or negative $(p=0.85)$ emotional memory.

Conclusions: The results of this study indicate that higher levels of SCORT during a memory encoding task in the 2nd trimester of pregnancy are associated with lower postpartum EPDS scores. While the hypothalamus-pituitary-adrenal (HPA) axis has long been associated with the neurobiology of MDD, the role of the HPA axis in perinatal depression deserves more attention.

Keywords: Pregnancy, postpartum depression, major depressive disorder, salivary cortisol, emotional memory.
\end{abstract}

\section{Resumo}

Introdução: A depressão pós-parto é um transtorno prevalente que afeta negativamente a qualidade de vida da mãe e da criança. Neste estudo longitudinal, nós investigamos se a memória emocional, o cortisol salivar (salivary cortisol, SCORT) ou alfa-amilase durante a gravidez predizem sintomas depressivos no período pós-parto.

Métodos: Um total de 44 mulheres grávidas [14 eutímicas com diagnóstico de transtorno depressivo maior (TDM) e 30 voluntárias sadias] entre 19 e 37 anos de idade (idade média $=29.5 \pm 4.1$ anos) foram avaliadas longitudinalmente no $2^{\circ}$ trimestre da gravidez (12-22 semanas de gestação) e na 1417 a semana pós-parto. Sintomas depressivos foram avaliados com a Escala de Depressão Pós-Natal de Edimburgo (Edinburgh Postnatal Depression Scale, EPDS).

Resultados: Quarenta e uma mulheres completaram o seguimento ( $7 \%$ de perda). sCORT coletado imediatamente antes de um teste de aquisição memória durante a gravidez foi preditor dos escores da escala EPDS no período pós-parto $(b=-$ $\left.0.78, t_{-2.14}, p=0.04\right)$. Memória emocional positiva $(p=0.27)$ ou negativa $(p=0.85)$ não foram preditores dos escores da escala EPDS no período pós-parto.

Conclusão: Os resultados deste estudo indicam que altos níveis de SCORT durante um teste de aquisição de memória no $2^{\circ}$ trimestre da gravidez foram associados com baixos escores na escala EPDS no período pós-parto. Uma vez que o eixo hipotálamo-hipófise-adrenal (HHA) tenha sido envolvido na neurobiologia do TDM, o papel do eixo HHA na depressão perinatal merece mais atenção.

Descritores: Gravidez, depressão pós-parto, transtorno depressivo maior, cortisol salivar, memória emocional.

\footnotetext{
${ }^{1}$ MiNDS Neuroscience Graduate Program, McMaster University, Hamilton, ON, Canada. ${ }^{2}$ Women's Health Concerns Clinic, St. Joseph's Healthcare Hamilton, Hamilton, ON, Canada. ${ }^{3}$ Mood Disorders Program, Department of Psychiatry and Behavioural Neurosciences, McMaster University, Hamilton, ON, Canada. This paper is based on an MSc thesis project for the MiNDS Neuroscience Graduate Program at McMaster University, wherein ME Williams was an MSc candidate and BN Frey was the graduate thesis supervisor.

Submitted Apr 09 2017, accepted for publication Aug 152017.

Suggested citation: Williams ME, Frey BN. Salivary cortisol during memory encoding in pregnancy predicts postpartum depressive symptoms: a longitudinal study. Trends Psychiatry Psychother. 2017;39(4):280-284. http://dx.doi.org/10.1590/2237-6089-2017-0032
} 


\section{Introduction}

Pregnancy and postpartum are particular vulnerable periods where the onset or exacerbation of depressive episodes is common and affects approximately $8 \%$ of Canadian women. ${ }^{1}$ While the hypothalamus-pituitaryadrenal (HPA) axis has long been associated with the neurobiology of major depressive disorder (MDD), the role of the HPA axis in perinatal depression is less known. ${ }^{2}$ Individuals with unipolar depression exhibit flattened diurnal cortisol rhythms and have a lower peak of awakening cortisol. ${ }^{3}$ It has been postulated that an augmented positive feedback loop leading to higher levels of cortisol and to placental corticotropin-releasing hormone $(\mathrm{pCRH})$ during pregnancy and a longer HPA refractory period in postpartum may be associated with increased risk for postpartum depression (PPD). ${ }^{2}$ Salivary cortisol (sCORT) awakening response in the 3rd trimester of pregnancy has been shown to negatively predict HPA stress responses in postpartum. ${ }^{4}$

Alpha-amylase is an enzyme that has been shown to be a marker of sympathetic nervous system activity as levels increase in humans in response to stressors. ${ }^{5}$ Inducing psychosocial stress in early 2nd and 3rd trimester pregnant women resulted in attenuation of alpha-amylase in the stress response compared to nonpregnant women and prolonged cortisol recovery in early 2 nd trimester pregnant women compared to early 3rd trimester pregnant and non-pregnant women. ${ }^{6}$ Many risk factors for PPD have been identified, including poor marital and social support, life stressors, low self-esteem, pessimism about pregnancy, and antenatal depression and anxiety. ${ }^{7-9}$ However, no biological markers have been clearly established in the genesis of this disorder.

This longitudinal study is a follow-up to a recent cross-sectional study where we found that euthymic women with a history of MDD had worse recognition memory than women without a lifetime history of MDD for negative, but not positive images, an effect that was independent of SCORT and salivary alpha-amylase (SAA) during incidental encoding. ${ }^{10}$ Given that previous studies have shown that elevated levels of SCORT and SAA during incidental encoding is associated with better memory for emotional content, ${ }^{11}$ and individuals currently depressed recall more negative compared to positive content, ${ }^{12}$ our results suggested that clinical remission may be associated with an opposite cognitive processing of negative emotional information. ${ }^{10}$

\section{Objectives and hypotheses}

The main objectives of this study were to investigate: 1) whether normalized memory sensitivity (for negative and positive images) during pregnancy predicted
Edinburgh Postnatal Depression Scale (EPDS) scores in postpartum; and 2) whether SCORT and SAA during pregnancy predicted EPDS scores in postpartum. We hypothesized that normalized memory sensitivity during pregnancy would be associated with higher EPDS scores in postpartum in participants with a history of MDD compared to participants without a history of MDD. We also hypothesized that salivary hormones (sCORT, sAA) during pregnancy would predict postpartum depressive symptoms (as measured by EPDS) in participants with a history of MDD.

\section{Methods}

\section{Sample}

Forty-four female participants were recruited at the Women's Health Concerns Clinic at St. Joseph's Healthcare Hamilton and a Community Midwives clinic in Hamilton, Ontario, Canada. All participants provided written informed consent and the study was approved by the St. Joseph's Healthcare Hamilton research ethics board. Detailed inclusion and exclusion criteria for the current sample can be found in a recent report. ${ }^{8}$ Of the 44 individuals initially enrolled in the study, three were unable to be contacted in postpartum. Therefore, a total of 41 pregnant participants between the ages of 19 and 37 years (mean age $=29.2 \pm 4.1$ years) completed the longitudinal study (13 euthymic pregnant women with a history of MDD and 28 pregnant women without a history of MDD). Participants were studied at 12-22 weeks of gestational age and 14-17 weeks of postpartum. The Structured Clinical Interview for DSM-IV (SCID-I) ${ }^{13}$ confirmed a past diagnosis of MDD in participants with a history of MDD. All women with a history of MDD were euthymic for at least 3 months prior to study entry.

\section{Measures}

Severity of depressive symptoms were assessed using the EPDS, ${ }^{14}$ anxiety symptoms using the StateTrait Anxiety Index (STAI), ${ }^{15}$ and sleep quality using the Pittsburgh Sleep Quality Index (PSQI). ${ }^{16}$ Incidental encoding and recognition memory tasks including positive, neutral, and negative images selected from the International Affective Picture System (IAPS) and sorbettes used to collect the salivary hormone samples are previously described. ${ }^{10}$ Collection time of samples was based on the participants' schedule and occurred between 10:00 and 19:00 hrs.

\section{Procedure}

The Salimetrics ${ }^{\circledR}$ Cortisol and a-Amylase Kinetic enzyme assay kits procedure instructions for 
quantifying SCORT and SAA, respectively, are described in detail elsewhere. ${ }^{17,18}$ SCORT and SAA samples were collected at four time points throughout the visit: 10 minutes before the incidental encoding task (time -1), immediately before the task (time 0), immediately after the task (time 1), and 10 minutes after the task (time 2). Participants returned a week later to complete the incidental recognition memory task. ${ }^{10}$ Participants were then contacted by phone at 14-17 weeks postpartum where they completed the EPDS and were re-administered the Major Depressive Episode module of the SCID-I to assess depressive symptoms and/or episodes.

\section{Data analysis}

Statistical analyses were performed using the Statistical Package for the Social Sciences version 21.0 for Windows. Differences in age, education, gestational age, anxiety symptoms (STAI) and sleep quality (PSQI) during pregnancy (Table 1) were analyzed using a oneway analysis of variance (ANOVA). For the incidental recognition memory task, Hit and False Alarm rates were calculated for each individual participant. These rates were in turn used to calculate the sensitivity indexes $\left(d^{\prime}\right)$ (for full details see Williams et al., 2015 ${ }^{10}$ ). The area under the curve with respect to ground $\left(\mathrm{AUC}_{\mathrm{G}}\right)$ was used to incorporate the four time points of hormonal collection. ${ }^{10}$

Multiple linear regression models were used to estimate the predictors of postpartum EPDS scores (dependent variable): 1 ) the relation between the cortisol $A \cup C_{G}$, which is the plot of cortisol vs. time, and the alpha-amylase $A_{U} C_{G}$, which is the plot of alphaamylase vs. time, during pregnancy and EPDS scores in postpartum; 2) the relation between recognition memory (i.e., normalized memory sensitivity) for positive and negative images during pregnancy and EPDS scores in postpartum; 3 ) the relation between sCORT samples collected 10 minutes before the incidental encoding memory task, immediately before the task, immediately after the task, and 10 minutes after the task, and postpartum EPDS scores; and 4) the relation between sAA samples collected 10 minutes before the incidental encoding memory task, immediately before the task, immediately after the task, and 10 minutes after the task, and postpartum EPDS scores. Group, $\mathrm{AUC}_{\mathrm{G}}$ for sCORT and SAA, normalized memory sensitivity (for positive and negative images), and SCORT and SAA samples collected 10 minutes before, immediately before, immediately after, and 10 minutes after the incidental encoding memory task were included as predictors.

\section{Results}

EPDS scores in postpartum were predicted by sCORT collected immediately after the incidental encoding memory task across groups during pregnancy $\left(b=-0.78, t_{-2.14}, p=0.04\right)$. This model explained $15 \%$ of the variance in EPDS scores in postpartum $\left(R^{2}=0.15\right.$, $\left.F_{5,40}=1.27, \mathrm{p}=0.04\right)$. These results indicate that higher levels of SCORT immediately after the incidental encoding memory task in pregnancy were associated with lower EPDS scores later in the postpartum period.

It is important to note that these results were positive in the whole sample. sCORT means for the high- and low-risk groups immediately after the task were 3.63 and $2.97 \mathrm{nmol} / \mathrm{L}$, respectively. However, there were no statistically significant differences in the prediction of postpartum EPDS scores between the high- and low-risk groups. Postpartum EPDS scores were not predicted by the cortisol $A \cup C_{G}\left(b=0.07, t_{0.45}\right.$, $\mathrm{p}=0.66)$ or the alpha-amylase $\mathrm{AUC}_{G}\left(\mathrm{~b}=-0.10, t_{-0.58}\right.$, $\mathrm{p}=0.57)$. Similarly, postpartum EPDS scores were not predicted by emotional memory for positive $(b=0.28$,

Table 1 - Demographic and clinical characteristics of participant groups during pregnancy

\begin{tabular}{lccc}
\hline Variable & $\begin{array}{c}\text { Pregnant \& MDD } \\
\text { history }\end{array}$ & $\begin{array}{c}\text { Pregnant \& no MDD } \\
\text { history }\end{array}$ & p \\
\hline Age (years) & $30.6(4.4)$ & $29.0(4.0)$ & 0.21 \\
Education (years) & $17.3(3.5)$ & $16.8(3.1)$ & 0.64 \\
STAI, state score & $27.79(5.46)$ & $25.11(3.21)$ & 0.05 \\
STAI, trait score & $35.29(6.33)$ & $30.53(3.36)$ & $0.002^{*}$ \\
PSQI & $4.43(2.77)$ & $4.62(2.16)$ & 0.81 \\
Gestational age (weeks) & $18.5(2.9)$ & $17.6(2.5)$ & 0.32 \\
Number of MDEs & $2.9(5.0)$ & N/A & N/A \\
\hline
\end{tabular}

Data presented as mean (standard deviation).

MDD = major depressive disorder $; \mathrm{MDE}=$ major depressive episode; $\mathrm{N} / \mathrm{A}=$ not applicable; $\mathrm{PSQI}=$ Pittsburgh Sleep Quality Index; STAI = State-Trait Anxiety Inventory.

* Significant at $\mathrm{p} \leq 0.01$. 
$\left.t_{1.12}, \mathrm{p}=0.27\right)$ or negative $\left(\mathrm{b}=-0.05, t_{-0.20}, \mathrm{p}=0.85\right)$ images. Three (7.3\%) women met diagnostic criteria for MDD in postpartum, two of whom had a previous history of MDD, a result that is consistent with the $8 \%$ prevalence of PPD previously reported in the Canadian population. ${ }^{1}$

\section{Discussion}

We found that higher levels of sCORT immediately after an incidental encoding memory task during pregnancy were associated with lower EPDS scores in postpartum across participant groups. A recent study found a positive association between EPDS scores $(\geq 10)$ and sCORT levels at 6 weeks postpartum, but no significant correlation between sCORT levels at 36 weeks of gestation and EPDS scores in late pregnancy and postpartum. ${ }^{19}$ In addition, another study found that higher levels of $\mathrm{pCRH}$ during mid-pregnancy were associated with depressive symptoms at 3-months postpartum. ${ }^{20}$ Together, these studies support the hypothesis that changes in certain HPA markers (sCORT and $\mathrm{pCRH}$ ) may be associated with increased depressive symptoms in the postpartum period. However, contrary to our hypothesis, we did not find an association between emotional memory during pregnancy and postpartum depressive symptoms.

A healthy pregnancy is characterized by increased levels of hormones, including SCORT, from early to late pregnancy, which typically normalize within 2 weeks postpartum. ${ }^{21}$ sCORT levels that do not normalize within this time may be linked to an increased risk for PPD. ${ }^{21}$ Postpartum EPDS scores were not predicted by the cortisol or the alpha-amylase $A_{U C}$. Differences in SCORT levels exist between depressed postpartum women and currently euthymic postpartum women within 30 minutes of awakening, but not at 3 and 12 hours after awakening. ${ }^{22}$ The fact that the samples were collected between 10:00 and 19:00 hrs during pregnancy (i.e., after 30 minutes of awakening) may be one of the reasons why cortisol $A U C_{G}$ did not predict changes in EPDS scores postpartum.

The exact etiology of PPD remains unclear. PPD is currently classified in the DSM-5 under the MDD umbrella with a specifier "with peripartum onset." 23 However, this classification continues to be questioned as there is evidence to suggest differential amygdala activation in postpartum compared to non-postpartum (unipolar) depression. Two independent studies found an association between blunted amygdala activation and PPD in response to emotional stimuli, ${ }^{24,25}$ which suggests that depression in the postpartum period may be qualitatively different than depression outside the postpartum period. Future longitudinal studies are needed to identify reliable markers of risk for the development of PPD as they serve as a preventative tool to screen and allow for early identification and treatment.

\section{Limitations}

Some methodological limitations that must be considered include a relatively small sample size, which may have limited our statistical power. Second, sCORT and SAA were collected at only one time point (2nd trimester of pregnancy) and not again in postpartum. This did not allow us to examine the possible association between changes in salivary hormones and postpartum depressive symptoms. Third, sample collection occurred according to the participants' availability, and not at standardized times for all participants. Strengths included the longitudinal design and the fact that most of the participants in the study ( $84 \%$ of the sample) were recruited from a Community Midwives clinic, which is less biased than results from samples originated from women treated in tertiary care centers.

\section{Acknowledgements}

This work was supported in kind by the Women's Health Concerns Clinic at St. Joseph's Healthcare Hamilton. We are grateful to the support from the Community Midwives clinic in Hamilton, and we would like to thank all the women who took part in the study, as this work would not have been possible without their ongoing participation.

\section{Disclosure}

No conflicts of interest declared concerning the publication of this article.

\section{References}

1. Dennis $\mathrm{CL}$, Heaman M, Vigod S. Epidemiology of postpartum depressive symptoms among Canadian women: regional and national results from a cross-sectional survey. Can J Psychiatry. 2012;57:537-46.

2. Glynn LM, Davis EP, Sandman CA. New insights into the role of perinatal HPA-axis dysregulation in postpartum depression. Neuropeptides. 2013;47:363-70.

3. McEwen BS. Physiology and neurobiology of stress and adaptation: central role of the brain. Physiol Rev. 2007;87:873-904. 
4. Meinlschmidt G, Martin C, Neumann ID, Heinrichs M. Maternal cortisol in late pregnancy and hypothalamic-pituitary-adrenal reactivity to psychosocial stress postpartum in women. Stress. 2010;13:163-71.

5. Petrakova L, Doering BK, Vits S, Engler H, Rief W, Schedlowski M, Grigoleit J. Psychosocial stress increases salivary alpha-amylase activity independently from plasma noradrenaline levels. PLoS One. 2015;10:e0134561.

6. Nierop A, Bratsikas A, Klinkenberg A, Nater UM, Zimmermann R, Ehlert $U$. Prolonged salivary cortisol recovery in second-trimester pregnant women and attenuated salivary a-amylase responses to psychosocial stress in human pregnancy. J Clin Endocrinol Metab. 2006;91:1329-35.

7. Milgrom J, Gemmill AW, Bilszta JL, Hayes B, Barnett B, Brooks J, et al. Antenatal risk factors for postnatal depression: a large prospective study. J Affect Disord. 2008;108:147-57.

8. O'Hara MW. Postpartum depression: what we know. J. Clin. Psychol. 2009;65:1258-69.

9. Norhayati MN, Hazlina NH, Asrenee AR, Emilin WM. Magnitude and risk factors for postpartum symptoms: a literature review. J Affect Disord. 2015;175:34-52.

10. Williams ME, Becker S, McKinnon MC, Wong Q, Cudney LE, Steiner $M$, et al. Emotional memory in pregnant women at risk for postpartum depression. Psychiatry Res. 2015;229:777-83.

11. Buchanan TW, Lovallo WR. Enhance memory for emotional material following stress-level cortisol treatment in humans. Psychoneuroendocrinology. 2001;26:307-17.

12. Hamilton JP, Gotlib IH. Neural substrates of increased memory sensitivity for negative stimuli in major depression. Biol Psychiatry. 2008;63:1155-62.

13. First MB, Spitzer RL, Gibbon M, Williams JBW. Structured Clinical Interview for DSM-IV-TR Axis-I Disorders, Research Version, Patient Edition (SCID-I/P). New York: Biometrics Research, New York State Psychiatric Institute; 2002.

14. Cox JL, Holden JM, Sagovsky R. Detection of postnatal depression. Development of the 10-item Edinburgh Postnatal Depression Scale. Br J Psychiatry. 1987;150:782-6.

15. Spielberger CDG, Lushene RE. Manual for the state-trait anxiety inventory. Palo Alto: Consulting Psychologists Press; 1970.

16. Buysse DJ, Reynolds CF, Monk TH, Berman SR, Kupfer DJ. The Pittsburgh Sleep Quality Index: a new instrument for psychiatric practice and research. Psychiatry Res. 1989;28:193-213.
17. Salimetrics. Expanded range high sensitivity salivary cortisol enzyme immunoassay kit [Internet]. State College: Salimetrics; 2016. [cited Mar 09 2017]. https://www.salimetrics.com/assets/ documents/1-3002n.pdf

18. Salimetrics. Salivary a-amylase kinetic enzyme assay kit [Internet]. State College: Salimetrics; 2016. [cited Mar 09 2017]. https://www.salimetrics.com/assets/documents/1-1902.pdf

19. Iliadis SI, Comasco E, Sylven S, Hellgren C, Sundstrom Poromaa I, Skalkidou A. Prenatal and postpartum evening salivary cortisol levels in association with peripartum depressive symptoms. PLoS One. 2015;10:e0135471.

20. Glynn LM, Sandman CA. Evaluation of the association between placental corticotrophin-releasing hormone and postpartum depressive symptoms. Psychosom Med. 2014;76:355-62.

21. KammererM, TaylorA, GloverV.TheHPAaxisandperinataldepression: A hypothesis. Arch Womens Ment Health. 2006;9:187-96.

22. de Rezende MG, Garcia-Leal C, de Figueiredo FP, de Carvalho Cavalli R, Spanghero MS, Barbieri MA, et al. Altered functioning of the HPA axis in depressed postpartum women. J Affect Disord. 2015;193:249-56.

23. American Psychiatric Association. Diagnostic and Statistical Manual of Mental Disorders, Fifth Edition (DSM-5). Arlington: American Psychiatric Publishing; 2013.

24. Moses-Kolko EL, Perlman SB, Wisner KL, James J, Saul AT, Phillips ML. Abnormally reduced dorsomedial prefrontal cortical activity and effective connectivity with amygdala in response to negative emotional faces in postpartum depression. Am J Psychiatry. 2010;167:1373-80.

25. Silverman ME, Loudon H, Liu X, Mauro C, Leiter G, Goldstein MA. The neural processing of negative emotion postpartum: a preliminary study of amygdala function in postpartum depression. Arch Womens Ment Health. 2011;14:355-9.

\section{Correspondence:}

Benicio N. Frey

Department of Psychiatry and Behavioural Neurosciences, McMaster University

100 West 5th Street, Suite C124

L8N 3K7 - Hamilton, ON - Canada

Tel.: + 1 (905) 522-1155, ext. 33605

E-mail: freybn@mcmaster.ca 